\section{Implications for Faculty}

As the courses of superstars are "unplugged" and offered on-line by for-profit companies worldwide, faculty teaching roles will change and there will be a decoupling of faculty from particular institutions.

The traditional control faculty exert over the curriculum design may become moot as colleges buy "Arthur Miller on a disk" or off-the-shelf products from brand-name curriculum factories like Amherst, Brown, or Williams. The strongest institutions will be these producers and wholesalers - the curriculum factories of the superstars. The rest will be the retailers with slimmer margins and greater dependency. While most faculty will become facilitators of these "world-class courses," the faculty who provide the intellectual capital for these ventures may become free agents teaching at hundreds of colleges and universities at once for extraordinary income from royalties or licenses. The richer the faculty member, the less value and claim tenure will hold. Joint appointments and regular movement between the academy and industry will increase as lines blur between independent and sponsored research, knowledge discovery, and knowledge transfer.

\section{Conclusion}

These trends and their impact on American higher education are likely to continue unless and until the higher education market responds negatively to runaway costs among high-end providers, to commercialization and profit motive in higher education, or to less-personalized, technology-driven delivery systems. None of these scenarios seem likely as long as the frontrunners, trend setters, and price leaders accumulate a greater advantage, or unless and until a demonstrable, empirical case can be made that any of these developments threaten the quality of higher education as gauged by any of its constituencies.

\title{
The Challenge of Lifelong Learning for Higher Education
}

\section{Barbara M. Kehm}

Barbara M. Kehm is on the staff of the Institute for Higher Education Research, University of Halle-Wittenberg, Collegienstr. 626, 06886 Lutherstadt Wittenberg, Germany. Fax: +49 - 3491 - 466 255. Email: <kehm@hof.uni-halle.de>.

\section{The Concept of Lifelong Learning}

Gupranational organizations like the OECD, UNESCO, and, in particular, the European Union are currently strongly promoting the concept of lifelong learning as a complement to the emergence of the "knowledge" society and the various social, economic, and educational changes it seems to entail. Many national governments in Europe have adopted the issue and given it a much more prominent position on their political agendas. Now more than ever, as centers of knowledge production and dissemination, higher education institutions are expected to play an important role in the provision and delivery of lifelong learning opportunities.

Within the context of lifelong learning, new objectives of education are being addressed. Beyond personal development with a reference to the individual, there are also additional objectives like social cohesion (in reference to society) and economic growth (in reference to market forces). Although a variety of interpretations are connected to the concept of lifelong learning, its core characteristics can be summarized as follows: a strong emphasis on the intrinsic rather than the instrumental value of education and learning; universal access to learning opportunities; recognition of learning in diverse settings and not only in educational institutions; learning throughout the lifespan; a diversity of methods of teaching and learning and modes of delivery unlike conventional education; a shift in emphasis from learning substance to learning process; and a shift from teaching to learning and from supply to demand in educational provisions.

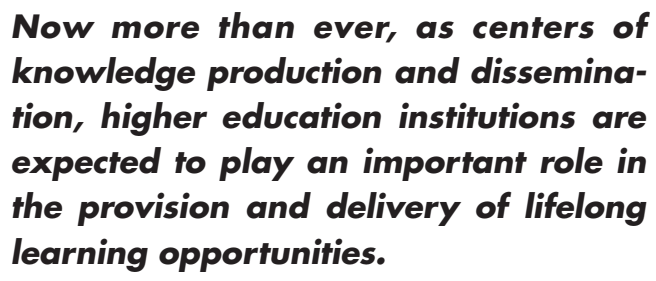

A recently completed research project about the implications of lifelong learning for universities in the EU, analyzing and comparing lifelong learning policies and practices in seven EU member states, has revealed considerable gaps between the rhetoric about and actual implementation of lifelong learning. These gaps are due to high expectations combined with a number of conceptual dilemmas and inconsistencies in developing relevant policies.

\section{Dilemmas and Inconsistencies}

The inconsistencies in lifelong learning as a concept derive from the fact that it is supposed to serve a number of contradictory objectives: as an instrument to enhance democratization, equality of opportunity, and social cohesion and as a way to improve the development of human resources (in EU policy terminology, "employability") in response to the demands of globalization and economic competitiveness. These dual aims of promoting equal- 
ity and enhancing competitiveness not only interfere with the traditional notions of a university education dedicated to the pursuit and dissemination of knowledge and truth, it is also doubtful that these aims can be realized at the same time and in the same institutional setting without compromising one or the other.

\section{The concept of knowledge within the frame- work of lifelong learning is informed by at least three different value patterns.}

The concept of knowledge within the framework of lifelong learning is informed by at least three different value patterns: a democratic concept of knowledge to enhance social inclusion, cohesion and participation; an economic concept of knowledge that serves income generation, wealth creation, and global competitiveness; and a concept of knowledge in which knowledge production in itself forms the point of departure.

It might be said, therefore, that lifelong learning tends to contribute to the fragmentation of knowledge, while at the same time enhancing the appropriation of knowledge by individual learners.

\section{Implications for Higher Education}

The concept of lifelong learning and related policies have a number of implications for the structure of higher education institutions and the organization of knowledge. Creating more learning opportunities for new and different categories of students means that students will no longer all start from a broadly shared knowledge base but will instead have acquired their knowledge from multiple sources and diverse types and fields of knowledge (family, work experience, etc.). The idea of exempting students from certain parts of a degree program-piloted in France and the United Kingdom - by accrediting their learning outside the academic system implies a shift toward varied and, to some extent, externally determined definitions of what constitutes a curriculum and, more importantly, a degree.

Accreditation of work-based and experiential learning threatens the legitimacy of knowledge organization in universities by replacing the regulating powers of disciplines and collegiality with multidisciplinary, dynamic, and more transient forms of knowledge formation. This shift is reinforced by the requirement that universities develop demand-led provisions of lifelong learning rather than continuing to offer supply-led forms, or-as is the case in Norway and Sweden-providing educational services that have been contracted or commissioned by companies for their employ- ees. Thus, the core functions of a curriculum will likely become the transmission and appropriation of transferable skills and competences that can be widely used and applied

The shift from knowledge to (transferable) skills parallels the shift from content to process. This implies a more action-oriented concept of knowledge in which issues of "learning to learn"-understanding one's own learning processes and identifying knowledge gaps and progress-will move into the foreground. The development of skills for learning seems to be a reaction to the growing obsolescence of established knowledge, which seems to be one of the key features of knowledge in the information society.

This shift in focus from knowledge to skills will also create new roles for teachers and learners. Teachers' expertise in higher education will no longer rest solely upon advanced specialist knowledge grounded primarily in discipline-based study and research but also upon an understanding of learning processes and the ability to convey the tranferability of their knowledge to a range of problems outside the academic world. Teachers will become "facilitators," helping learners to become "reflective practitioners." Not only will "knowing" be conceptualized as various forms of action (problem solving, decision making, etc.), but it will also cut through traditional distinctions between theory and practice, knowledge and skills.

These are but a few of the implications of lifelong learning and the new concepts of knowledge linked to it. If knowledge becomes a substantially more social and more directly economic production, what can, should, or must universities do to secure their institutional and functional survival?

\section{Lifelong Learning as Threat or Challenge?}

The European comparative study about the implications of lifelong learning for universities has shown one clear trend in all seven of the countries included. Regardless of the varying extent to which traditional notions of continuing (professional) education are integrated and accepted within the frameworks of university education, institutions typically tend to react to the new challenges linked to the concept of lifelong learning and its implications for the organization of knowledge in two ways. On the one hand, they realize that rejecting the idea of lifelong learning has become "politically incorrect" and have adopted it on a policy level. In the absence of any real leadership, however, institutions often struggle with lack of structures, funds, and incentives. The demand to implement the new concepts linked to the idea of lifelong learning is often met by rhetoric and a simple replacement of the term "continuing education" by that of "lifelong learning" without any change in practices and provisions. On the other hand, many diverse pilot projects, experiments, and new models are integrating the concept of lifelong learning into university programs 
and making it part of the structure of tertiary education. Examples include the United Kingdom and France, which are quite advanced in the development of procedures to recognize and accredit work-based learning; Germany, which has numerous special university provisions for senior citizens; Greece, which has established an open university; and Sweden and Norway, which tend to rely on their established quota systems for older students. Despite continuing skepticism among academic teachers, the issue of lifelong learning has become part of the ongoing reform agenda in Europe, part of efforts universities are undertaking to improve their interaction and cooperation with their environment and with a wider range of external stakeholders.

\section{Should Universities in Developing Countries Stop Doing R\&D?}

\section{Armando Alcantara}

Armando Alcantara is professor at the Center for University Studies, Universidad Nacional Autonoma de Mexico. He is a visiting scholar in the Center for International Higher Eduation at Boston College during the 2000-2001 academic year. Address: CIHE, Campion Hall, Boston College, Chestnut Hill, MA 02467 USA. E-mail: <armando.alcantara@bc.edu>.

A $\mathrm{s}$ we witness the transformation of many developed nations into knowledge-based societies, the difficulties for developing countries trying to catch up seem insurmountable. Research universities-along with other publicand private-sector institutions in the industrialized world-continue to develop technology products at unprecedented pace. At present, the world is thus observing how the gulf between developed and developing countries keeps widening. While industrialized nations such as the United States, Japan, and the countries in Western Europe invest between 2 and 3 percent of their GDP in research and development $(\mathrm{R} \& \mathrm{D})$, the countries of the developing world rarely reach 1 percent on the same indicator. The close link between industry and university $R \& D$ in the developed world makes scientific and technological research an important tool for economic development. More often than not, however, university $\mathrm{R} \& \mathrm{D}$ in developing nations lacks effective demand from local industry, making it basically academia oriented. This situation is especially disturbing when university research does not contribute significantly to the solution of urgent local societal needs.

Some countries of the Third World are trying to replicate the successful experiences of Korea, Taiwan, Singapore, and Malaysia, countries that have proven that it is possible to achieve economic growth based on the contributions of local R\&D. It has not been possible thus far to achieve successful results because the coordination of government, universities, and local industry in a clear innovative strategy has not occurred. As a consequence, the viability of developing countries' R\&D is an issue of growing concern among scholars, scientists, and policymakers.

Latin America and, more particularly, Argentina and Mexico, are cases that illustrate the current situation of R\&D within the developing world. The knowledge produced in Latin America represents less than 3 percent of the world's sci- entific production. This is not surprising given its low investment in R\&D. Public expenditures in R\&D of all Latin American countries are equivalent to the expenses in $R \& D$ of merely a couple of multinational corporations. In Argentina and Mexico-the countries in the region that (along with Brazil) have a tradition of and personnel in $R \& D-R \& D$ investments have remained significantly low (less than 0.5 percent of GDP). The number of scientists and engineers in $\mathrm{R} \& \mathrm{D}$ is also low (between 14,000 and 16,500), while in the industrialized countries it reaches figures above 50,000. Other indicators show that most R\&D funds in Argentina and Mexico come from public money (more than 80 percent). There are very few graduates at the doctoral level training for careers in research. Consequently, with very limited resources and small R\&D communities, the output is irrelevant when measured by the number of patents granted to residents and nonresidents. In relation to this indicator, royalties and license fees payments are much higher than receipts.

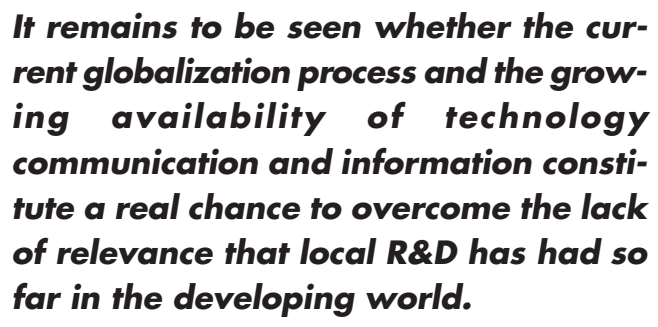

It is also worth mentioning that $R \& D$ in Argentina and Mexico occurs at the large, publicly funded universities. Argentina's University of Buenos Aires (UBA) and Mexico's National Autonomous University (UNAM) are, along with Brazil's University of Sao Paulo and University of Campinas, among the most prestigious institutions for scientific research in Latin America. Despite having the oldest research tradition and employing the largest number of scientists (many of whom are highly distinguished), UBA and UNAM are also too large, with enrollments near and above 200,000 students, respectively, and are plagued by tight budgets, excessive bureaucracy, overpolitization, weak 